Claudia Kayat, Claudio Magalhães *

\title{
Experimentos biomiméticos e novas tecnologias digitais para o design de embalagem
}

Claudia Kayat

Mestre em Design; Departamento de Artes \& Design - PUC-Rio <claudiakayat@puc-rio.br>

Claudio Magalhães

Doutor em Design; Departamento de Artes \& Design - PUC-Rio <claudio-design@puc-rio.br>
Resumo A presente pesquisa possui característica exploratória, voltada a investigar se novas tecnologias digitais (microtomografia, impressão 3D) potencializam abordagens de pensar e projetar embalagem por meio de analogias entre biologia e design (biomimética). A pesquisa baseou-se em dois experimentos, nos quais foi aplicado o pensamento biomimético baseado na abordagem "biologia para projetar" (Biomimicry 3.8, 2007): Experimento A, sem uso de novas tecnologias, e Experimento B, com uso de novas tecnologias digitais. Ao final, graças ao processo de design exploratório e experimental - amparado pelo uso de novas tecnologias digitais - chegou-se a um conceito inovador para o design de embalagem.

Palavras chave Biomimética; Novas tecnologias (microtomografia, impressão 3D); Embalagem.

\section{Biomimetic experiments and the new digital technologies for packaging design}

Abstract This research has an exploratory characteristic, aimed to investigate whether the new digital technologies (specially microtomography and 3D printing) potentializes the approaches of thinking and designing packaging through analogies between biology and design (Biomimicry). This research was held in two experiments who applied the biomimetic based thinking approach "Biology to Design" (Biomimicry 3.8, 2007). Experiment $A$, without the use of new technologies and Experiment $B$, with the use of new digital technologies. In the end, thanks to the exploratory and experimental process, supported by the use of new digital technologies enhancing Biomimietics, an innovative concept for packaging design was achieved.

Keywords Biomimetics; New Technologies (microtomography,3D printing); Packaging. 


\section{Analogias entre biologia e design de embalagem, e as novas tecnologias digitais}

Embalagens são inevitáveis na vida moderna. Elas preservam e protegem, permitindo às pessoas fazerem uso de produtos que foram produzidas longe ou há algum tempo.

A Organização Mundial da Embalagem (WPO) ${ }^{1}$ afirma que a embalagem é uma ferramenta que viabiliza a sociedade atual e que deve estar aliada à preservação da vida, da saúde e dos recursos naturais e que seu avanço tecnológico é guiado pela busca de "melhor qualidade de vida por meio de melhores embalagens para mais pessoas" (WPO, 2011). Ainda, segundo posicionamento da WPO no paper "Packaging - An important tool for a sustainable society" (2011), nos últimos vinte anos as indústrias de embalagens vêm lidando com problemas cada vez mais complexos, que impõem soluções de embalagens mais eficientes ambientalmente, ou seja, que reduzam o uso de matéria-prima e energia, que sejam recicláveis e reutilizadas.

A busca por inspiração na natureza para solucionar problemas complexos estimulou áreas de conhecimento transdisciplinares que exploram o uso de analogias biológicas na atividade de projetar. Designers, arquitetos e engenheiros, vêm se interessando por essa abordagem, há muito tempo. Nos últimos cem anos, especialmente depois da segunda guerra mundial, os cientistas começaram a pesquisar nas ciências biológicas respostas para problemas humanos e obtiveram excelentes resultados.

O biólogo e matemático escocês Darcy Thompson, em seu livro On Growth and Form, 1917, explorou diversas geometrias de organismos naturais (Figura 1) e sua dinâmica de crescimento e processos físicos. Seus estudos influenciaram arquitetos, entre eles, Calatrava, Frei Otto, Renzo Piano, a terem como objetivo projetual o uso de princípios construtivos dos organismos presentes na natureza.

Figura 1 - Imagem de geometrias de organismos naturais

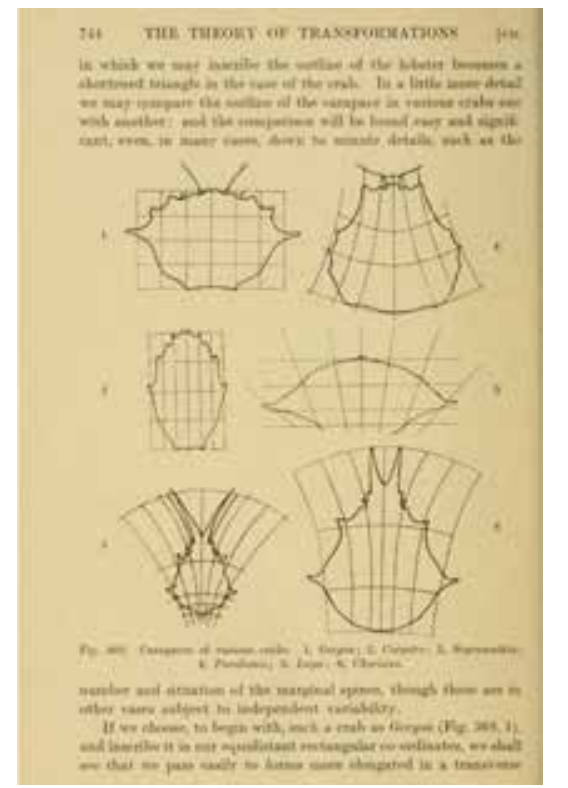

Fonte: On Growth and Form, 1917.

${ }^{1}$ www.worldpackaging.org 
No âmbito das embalagens, Benyus mapeou, em seu artigo Packaging Tips from the Porcupine Fish (2002), várias estratégias de organismos vivos quanto à proteção: impacto, arranhões e quedas, etc... Podemos citar uma dessas estratégias: folhas e sementes estão organizadas em uma sequência espiral (conhecida por sequência de Fibonacci) que permite um "embalamento" uniforme em qualquer fase de seu crescimento, ou seja, sem encher demais no centro e nem espalhar muito nas pontas (Benyus, 2002).

É comum ouvirmos relatos acerca de como a natureza "embala" bem, e o quão bom seria se projetássemos embalagens tão perfeitas como as que encontramos no mundo natural: que protegem, facilitam o transporte e são naturalmente biodegradáveis.

Por meio de analogias com a natureza podemos transferir informação e significado de um sujeito particular (natureza) para outro sujeito particular (por ex.: embalagem).

Ilustramos, com a imagem abaixo (Figura 2), o uso de analogia no design de embalagem, ou seja, como a natureza comunica que a banana está estragada por meio de manchas e a transferência dessa "solução" para o rótulo de remédios, comunicando que o mesmo está fora da validade.

Figura 2 - Design gráfico de embalagem para remédios, usando analogia com a natureza.

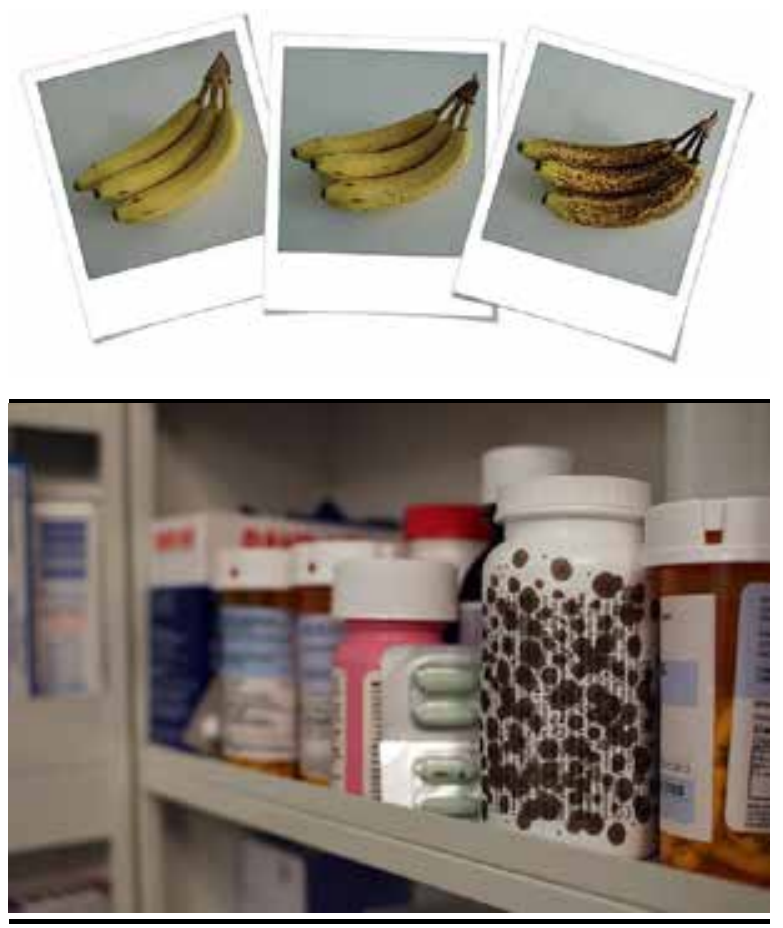

Fonte: $<$ http://www.pinterest.com/pin/282178732877521603/>. Acessado em: 20 nov. 2014

O processo cognitivo envolvido na formação de analogias é importante para melhorar o processo de design biomimético. Os psicólogos americanos Gentner e Markman (1997) fizeram diversas pesquisas para entender o processo cognitivo que as pessoas usam para criar e entender analogias e metáforas. Descobriram que é um processo baseado principalmente em observação, associações, comparações, correspondências, semelhanças, similitudes, memória e combinação de conceitos que em princípio não estavam relacionados, gerando assim, soluções, ideias originais e inovações. Em sua pesquisa Structure Mapping in Analogy and Similarity, os pesquisadores explicam que o processo começa quando uma pessoa aprende um 
novo conhecimento e codifica a Fonte de inspiração para um problema futuro. Em algum momento do futuro, a pessoa se depara com um novo problema e deve recuperar (lembrar-se), de uma Fonte adequada de ideia para resolver o novo problema. Esse é o passo mais difícil cognitivamente do processo: recuperar uma analogia útil. Uma vez que uma Fonte é lembrada, um mapeamento é criado entre a Fonte e a nova situação Alvo. Ao desenvolvermos esses mapeamentos, criamos novas ideias. (Gentner e Markman, 1997).

Analogias, portanto, tem papel significativo e estratégico na resolução de problemas, tomada de decisão, percepção, memória, comunicação, criatividade e inovação, e conhecer as estratégias da natureza, - fotossíntese, automontagem, seleção natural, ecossistemas autosustentáveis, olhos, ouvidos, peles, conchas, neurônios, terapias naturais e outras coisas mais, abre uma ampla gama de possibilidades inventivas ao homem (Benyus, 2003).

A literatura científica, a partir de 1960, cunhou diferentes termos para caracterizar esse processo de busca de inspiração em modelos naturais, sistemas e processos para resolver problemas humanos. São eles: biônica, biomimética, biomimesi, biognosis, bioinspiration, design bioanalogous, design biologicamente inspirado, biomimcry. Esses termos são muitas vezes considerados como sinônimos.

O termo biomimética foi cunhado por Janine M. Benyus, cientista e bióloga americana, autora do livro: Biomimética - Inovação Inspirada pela Natureza, 2003, que afirmou:

A Biomimética usa um padrão ecológico para ajuizar a 'correção' das nossas inovações. Após 3,8 bilhões de anos de evolução, a natureza aprendeu: O que funciona. O que é apropriado. O que dura. (BENYUS, 2003, p.15)

Porém, para que a prática do design biomimético seja adotada por mais projetistas e implementada em organizações empresariais de forma sistemática e consistente, são necessários métodos e tecnologias que ampliem o conhecimento biológico, apoiem a transferência desse conhecimento para a solução de problemas, e facilitem o uso de analogias com a natureza, para gerar ideias e criar valor (Shu, 2011).

As novas tecnologias digitais estão provocando mudanças sísmicas nas economias mundiais. Elas oferecem uma nova forma de aproximação e abordagem para lidar com a complexidade dos dias atuais, pois permitem comunicação ágil em rede, visualização e análise de dados, mudança de modelo fabril e de manufatura, entre outros.

Por exemplo, essas novas tecnologias estão permitindo duplicar a cada cinco anos os conhecimentos da biologia e das ciências naturais a partir da ampliação do alcance da visão. Benyus, afirma:

Igualmente sem precedentes é o alcance da nossa visão: novos alcances e satélites
facultam-nos a observação dos padrões da natureza, do interstício celular às
vastidões interestrelares. Podemos sondar um ranúnculo com os olhos de um ácaro,
pegar carona na viagem dos elétrons da fotossíntese, sentir a vibração de um
neurônio em atividade ou assistir em cores, ao nascimento de uma estrela. Podemos
ver, mais claramente do que nunca, como a natureza realiza seus milagres.
(BENYUS, 2003, p.14).

Podemos também destacar o grande avanço na medicina no que se refere a obtenção e visualização de imagens bem definidas do corpo humano, por meio de tecnologias não invasivas, como aquisição de imagens por ressonância magnética (RM) e tratamento digital, para que sejam representadas tridimensionalmente usando-se impressoras $3 \mathrm{D}$ de alta precisão.

Durante alguns anos, a partir de seu invento em 1591, o microscópio foi um equipamento essencial para a investigação da natureza. $\mathrm{O}$ mais moderno atualmente é o 
microscópio eletrônico de varredura que é utilizado para observar detalhes da superfície de objetos sólidos e é capaz de ampliá-las em até 300 mil vezes. A imagem pode ser tridimensional e registrada em vídeos e fotografias.

Os biólogos usam esses equipamentos a fim de ampliar o conhecimento científico sobre células no corpo do ser vivo, fornecendo às áreas de anatomia, organografia, histoquímica e fitopatologia, subsídios que poderão ser utilizados em melhoramento vegetal.

Os engenheiros de materiais usam microtomógrafos para verificar falhas microestruturais de materiais, a porosidade de metais, e o comportamento de peças sob condições variadas de pressão, temperatura e umidade.

Recentemente, alguns poucos designers usam os mesmos equipamentos para se inspirar com a inteligência da natureza e aplicá-la em projetos de design. Marko Brajovic e Guto Requena são uns desses designers que usam novos paradigmas orgânicos (possíveis por meio de novas tecnologias) programando formas a partir de emoções e imagens em nanoescala da natureza.

A presente pesquisa teve uma característica exploratória, voltada a investigar se abordagens de pensar e projetar embalagens por meio de analogias entre biologia e design (biomimética) são potencializadas por novas tecnologias digitais (especialmente microtomografia e impressão 3D). E também, uma característica experimental, objetivando estimular a criação e materialização de conceitos inovadores biomiméticos, para embalagem.

\section{Métodos}

Os métodos de pesquisa escolhidos foram: (1) pesquisa bibliográfica sobre biomimética, processo de design, analogias e embalagens (em livros, artigos, internet; principalmente duas bases de dados: a ISI Web of Science e a Science Direct, ambas por sua abrangência e qualidade; (2) pesquisa de campo em ambientes naturais, principalmente no Jardim Botânico do Rio de Janeiro, para observações intuitivas sobre elementos da natureza (dados primários), entrevistas com biólogos, para absorver seu processo de trabalho e adquirir experiência; (3) pesquisas em bancos de dados biológicos (principalmente Asknature ${ }^{2}$ ), que proporcionam conhecimentos abrangentes sobre a vida na terra e que auxiliam o entendimento das estratégias da natureza; (4) experimentos baseados na abordagem metodológica Biomimicry Design Lens (lentes biomiméticas), especialmente o modelo Biology to design (biologia para projetar) do Biomimicry 3.8 (2013).

A opção por fazer os experimentos baseado nas lentes biomiméticas do Biomimicry 3.8 (2013), deve-se ao fato da existência de diversas plataformas para disseminar a importância da inovação inspirada na natureza: livros, vídeos, bases de dados on-line, sites (www.biomimicry.net e www.asknature.org), e produção de diversos materiais didáticos, tanto para educação básica como para formação de especialistas em biomimética. Essa base de dados foi importante para os processos de aproximação adotados nesta pesquisa. Além disso, Benyus presta consultorias para pesquisadores na área e empresas que pretendem inovar utilizando a biomimética, entre elas algumas reconhecidas empresas brasileiras.

As lentes biomiméticas propõem duas abordagens no pensamento biomimético. A primeira, Challenge to Biology (desafio para a biologia), é útil para cenários onde o problema está bem definido e procuram-se insights biológicos para solucioná-lo. Deve ser aplicado em um ambiente "controlado" como uma sala de aula.

\footnotetext{
${ }^{2}$ www.asknature.org
} 
A segunda abordagem, Biology to Design (biologia para projetar), é mais apropriada quando se tem um insight biológico que você quer manifestar em um design. É recomendada a aplicação por inventores, empreendedores e profissionais interessados na interdisciplinaridade. Portanto, acreditou-se ser a segunda abordagem a mais adequada como base metodológica para essa pesquisa, que tem uma forte característica experimental, objetivando a criação e materialização de conceitos inovadores biomiméticos, para embalagem.

Cabe destacar que o experimento nessa pesquisa foi estruturado em dois processos visando avaliar a influência do uso de novas tecnologias digitais: Experimento A (sem uso de novas tecnologias digitais), e Experimento B (com uso de novas tecnologias digitais).

O Experimento A abrangeu as seguintes etapas: descobrir modelos naturais (A1); selecionar organismo inspirador (A2); abstrair estratégias biológicas (A3); identificar função e definir contexto (A4); brainstorm ideias bioinspiradas (A5).

Como o Experimento B foi realizado a partir do mesmo organismo inspirador, não foi necessário repetir as etapas de descoberta de modelos naturais e seleção do organismo inspirador, já realizados no Experimento A. O Experimento B, portanto, abrangeu as seguintes etapas: abstrair estratégias biológicas (B1); identificar função e definir contexto (B2); brainstorm 1 - primeiras ideias bioinspiradas (B3); emular conceitos de design do brainstorm 1 (B4); brainstorm 2 - novas ideias bioinspiradas (B5); emular conceitos de design do brainstorm 2 (B6); explorar e validar o conceito de design mais promissor para inovação de embalagem bioinspirada (B7).

\section{Experimento $\mathrm{A}$}

O Experimento A foi realizado a partir do pensamento biomimético, "biologia para projetar" (Biomimicry 3.8, 2007), e não foram utilizadas novas tecnologias digitais, como microtomógrafo e impressora 3D.

As seguintes atividades foram executadas nas seguintes etapas: (A1) descobrir modelos naturais; (A2) selecionar organismo inspirador; (A3) abstrair estratégias biológicas; (A4) identificar função e definir contexto; (A5) brainstorm ideias bioinspiradas.

A Etapa A1 consistiu em descobrir um organismo, ou ecosistema inspirador, e aprender sobre suas estratégias para evoluir e sobreviver. Buscou-se inspiração na natureza, especialmente na Botânica, e seu reino das plantas: raiz, caule, folha, flor, fruto e semente, considerando-se os inúmeros exemplos de "boas embalagens" presentes no mesmo. As angiospermas foram estudadas e diversos frutos foram coletados no arboreto do Jardim Botânico do Rio de Janeiro e em visitas guiadas por biólogos à Mata Atlântica, para observação e manuseio. Também foram consultadas bases de dados virtuais sobre biomimética e estudo de casos.

As atividades dessa Etapa A1 consistiram em, após descoberto o organismo inspirador (reino das plantas), conhecer suas variadas estratégias quanto à proteção, acomodação, contenção, armazenagem, distribuição e transporte, a fim de posteriormente transferí-las, por analogia, para o design de embalagem.

Para tanto, foi necessário acessar um espaço amplo de conhecimento na biologia (dados secundários), e também imergir na natureza (dados primários), observando e perguntando-se, por exemplo, como um determinado fruto faz para acomodar, proteger, distribuir e liberar suas sementes? 
Realizou-se, portanto, nessa etapa A1: (A1.1) pesquisa bibliográfica; (A1.2) visitas a instituições de pesquisa biológica; (A1.3) entrevistas com biólogos; (A1.4) observações da natureza em parques, florestas, matas, etc... (A1.5) coleta de material biológico, tais como: flores, frutos, sementes (Figura 3); (A1.6) análise do material biológico, sem uso de novas tecnologias; (A1.7) pesquisa documental em bases de dados virtuais sobre biomimética e estudo de casos.

Figura 3 - Amostras de Clusia Lanceolata coletadas em visita ao arboreto do JBRJ

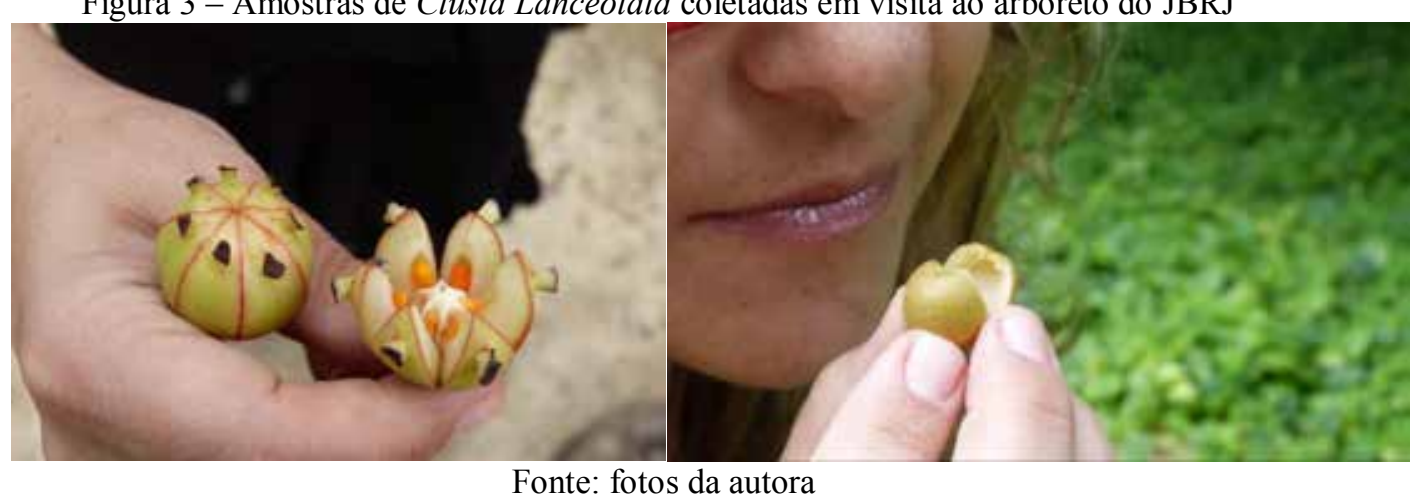

Buscou-se na pesquisa bibliográfica, informações científicas básicas sobre nossa área de inspiração: a Botânica, especialmente a classe das angiospermas: "plantas com flores e que também se caracterizam por darem às suas sementes uma proteção extra, encerrando-as em uma estrutura que chamamos técnicamente de fruto". (OLIVEIRA, 2008, pg 201).

A etapa A2 tratou de selecionar um organismo inspirador. Escolheu-se como inspiração o fruto do amendoim (pertencente à família das Angiospermas Fabaceae também conhecida como Leguminosae), por tratar-se de um fruto leguminoso (Figura 4) com peculiaridades em relação a acomodação, proteção e conservação de suas sementes, entre elas: leveza, resistência, impermeabilidade, abertura facilitada e adaptabilidade a diferentes quantidades de sementes.

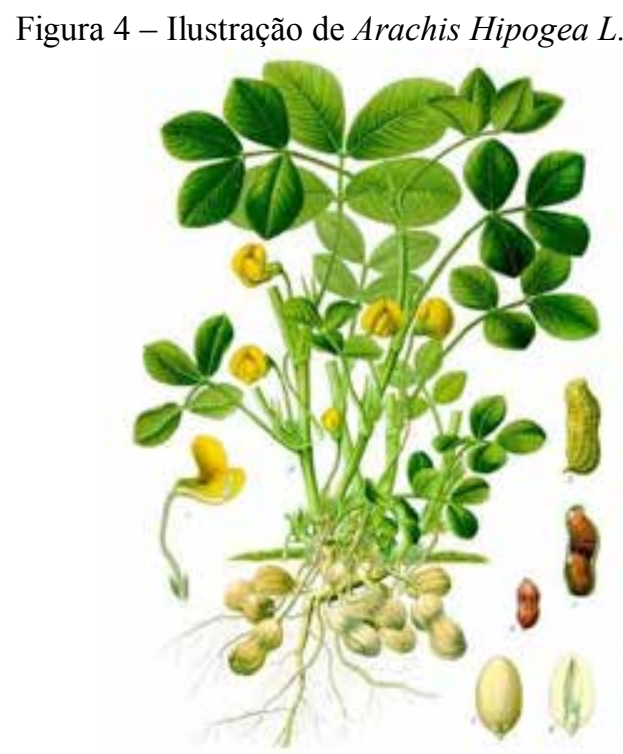

Fonte: Disponível em www.plantillustration.org. Acessado em 7 dez 2015. 
Em seguida, na etapa A3, com o apoio de um biólogo e de uma análise morfológica, procurou-se abstrair as estratégias biológicas usadas pelo amendoim, para evoluir e sobreviver (Quadro 1).

\begin{tabular}{|l|l|}
\hline \multicolumn{2}{|c|}{ Quadro 1 - Síntese das estratégias biológicas abstraídas da vagem do amendoim } \\
\hline VAGEM DO AMENDOIM & Estratégias biológicas abstraídas \\
\hline Forma integral, adaptável a diferentes quantidades de sementes. \\
\hline
\end{tabular}

Fonte: quadro da autora

A etapa A4 visou entender as funções do fruto do amendoim. Tratou-se de identificar uma característica, mecanismo, processo, que faz alguma coisa (uma função) para esse organismo. São as "coisas" que a estratégia faz para o organismo, e o contexto onde essa função é desejada (Quadro 2). 
Quadro 2 - Estratégias biológicas da vagem do amendoim e funções

\section{VAGEM DO AMENDOIM}

\begin{tabular}{|l|l|}
\hline Estratégias biológicas abstraídas & Funções \\
\hline Forma integral, adaptável a diferentes quantidades de sementes. & Permitir adaptações dimensionais \\
\hline $\begin{array}{l}\text { Fragilidade na região longitudinal da vagem, } \\
\text { que "quebra" por meio de pressão, } \\
\text { disponibilizando as sementes sem danificá-las. }\end{array}$ & $\begin{array}{l}\text { Abrir, permitindo acesso ao conteúdo quando } \\
\text { desejado e sem danificá-lo. }\end{array}$ \\
\hline $\begin{array}{l}\text { Amadurecimento do fruto embaixo da terra, } \\
\text { permitindo proteção contra predadores. }\end{array}$ & $\begin{array}{l}\text { Promover segurança ao conteúdo contra } \\
\text { agentes externos. }\end{array}$ \\
\hline $\begin{array}{l}\text { Impermeabilidade } \\
\text { Casca rígida, composta por conjunto de fibras longitudinais e } \\
\text { multicamadas de materiais. }\end{array}$ & \begin{tabular}{l} 
Proteger contra umidade. \\
\hline Casca leve, devido à diminuição da espessura nas depressões.
\end{tabular} \\
\hline
\end{tabular}

Fonte: quadro da autora

Abstraídas as estratégias e definidas as funções do fruto do amendoim, geraram-se, por analogia, ideias para embalagens (Etapa A5). Abaixo figura que apresenta alguns desenhos das ideias geradas (Figura 5).

Figura 5 - Sketches com geração de ideias a partir da transferência de estratégias

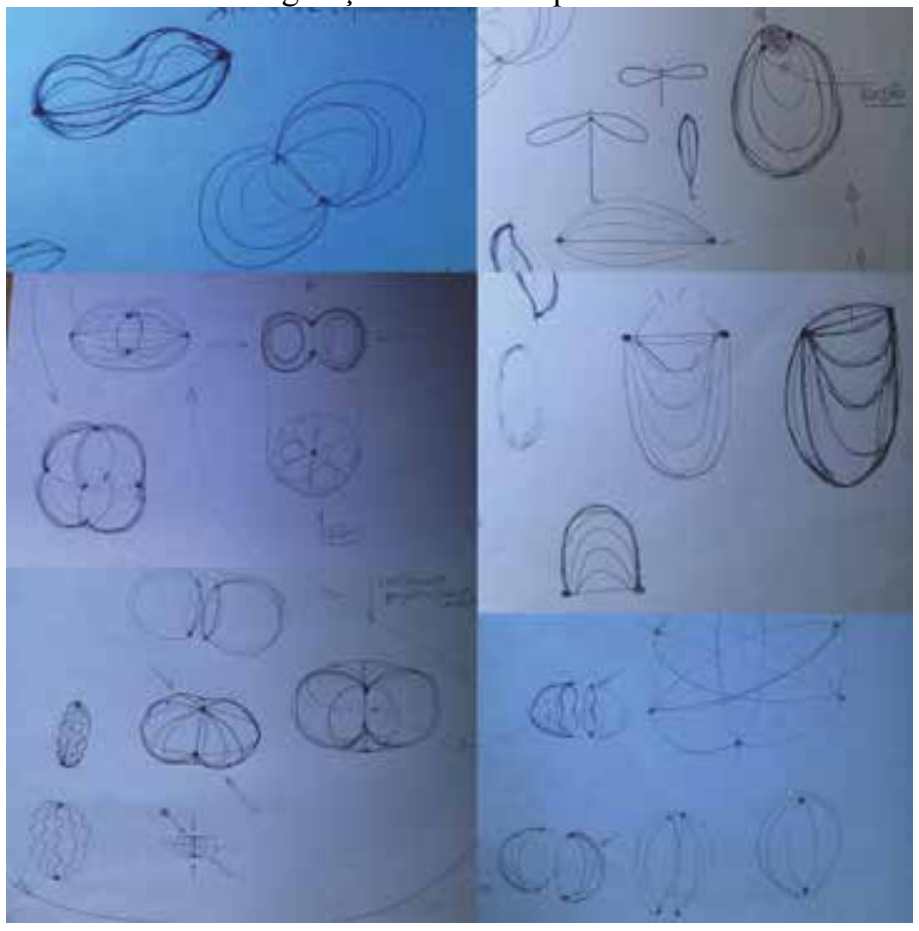

Fonte: desenhos da autora 


\section{Conclusão Experimento A}

O Experimento A abrangeu as seguintes etapas: descobrir modelos naturais (A1); selecionar organismo inspirador (A2); abstrair estratégias biológicas (A3); identificar função e definir contexto (A4); brainstorm ideias bioinspiradas (A5). Foi realizada a partir do pensamento biomimético, "biologia para projetar" (Biomimicry 3.8, 2007), porém, diferentemente do método usado pelo Biomimicry 3.8, não avançou-se nas etapas posteriores ao brainstorm. A autora avalia ser necessário esse avanço futuramente, para uma análise comparativa mais aprofundada sobre os resultados com e sem uso das novas tecnologias digitais, pois, no Experimento A, não foram utilizadas novas tecnologias digitais (microtomógrafo e impressora 3D), e no Experimento B usou-se essas tecnologias.

Constatou-se que foi fundamental o apoio do biólogo em visitas ao Jardim Botânico e na orientação teórica sobre o Reino da Plantas (Angiospermas), durante a Etapa A1 (descobrir um organismo ou ecosistema inspirador, e aprender sobre suas estratégias para evoluir e sobreviver).

A escolha do fruto do amendoim como organismo inspirador, mostrou-se acertada, pois as abstrações de suas estratégias biológicas geraram insights sobre as funções e o contexto onde as mesmas são desejadas, no caso dessa pesquisa, o design de embalagem.

É importante ressaltar que nesse experimento não houve o apoio das novas tecnologias digitais, portanto, foi muito importante a experiência da autora como designer para, a "olho nú", realizar uma análise morfológica e abstrair as estratégias do organismo e posteriormente entender as "coisas" que a estratégia faz para o organismo (funções), e o contexto onde essas funções são desejadas. Abstraídas as estratégias e definidas as funções do fruto do amendoim, geraram-se ideias para embalagens, porém com analogias muito próximas aos aspectos formais e estruturais, perceptíveis a "olho nú", do fruto do amendoim.

\section{Experimento B}

O Experimento B caracteriza-se pelo intenso uso de novas tecnologias digitais, como microtomógrafo e impressora 3D. Usou-se como base metodológica o pensamento biomimético - "biologia para projetar" (Biomimicry 3.8, 2007). Também executou-se uma etapa de validação do conceito de design mais promissor para inovação de embalagem bioinspirada.

Como o Experimento B foi realizado a partir do mesmo organismo inspirador (o fruto do amendoim), não foi necessário repetir as etapas de descoberta de modelos naturais e seleção do organismo inspirador. O Experimento B, portanto, abrangeu as seguintes etapas: abstrair estratégias biológicas (B1); identificar função e definir contexto (B2); brainstorm 1 primeiras ideias bioinspiradas (B3); emular conceitos de design do brainstorm 1 (B4); brainstorm 2 - novas ideias bioinspiradas (B5); emular conceitos de design do brainstorm 2 (B6); explorar e validar o conceito de design mais promissor para inovação de embalagem bioinspirada (B7).

A etapa B1 consistiu em abstrair as estratégias biológicas usadas pelo amendoim para evoluir e sobreviver, por meio do uso intenso de novas tecnologias digitais de aquisição de imagens pela microtomografia, digitalização das mesmas e materialização por impressão 3D.

Nessa pesquisa foram utilizadas as seguintes novas tecnologias digitais a fim de gerar inúmeros e confiáveis dados primários sobre o fruto do amendoim. São elas: aquisição de imagem por meio de microtomografia (software Scout and Scan Control System), reconstrução da imagem (software XM Reconstructor Cobe Beam 10), tratamento dessas imagens digitalmente (softwares Fiji e Geomagic), modelagem tridimensional (softwares 
Rhinoceros e Solidworks), prototipagem rápida em impressoras 3D. As impressoras 3D usadas nesta pesquisa foram: CubePro, Felix e MakerBot. Os filamentos utilizados foram PLA (Poliácido Lático - produzido a partir de fontes naturais como milho e cana-de-açúcar), ABS (Copolímero de Acrilonitrila e Estireno) e NinjaFlex (elastômero termoplástico).

O microtomógrafo utiliza a mesma técnica da tomografia hospitalar, porém em pequena escala e com aumento exponencial da resolução. A microtomografia é uma espécie de radiografia em 3D, permitindo uma visualização não destrutiva e em alta resolução $3 \mathrm{D}$ da estrutura interna de objetos.

Um importante diferencial dessa pesquisa é o uso de microtomografia computadorizada para investigação de materiais biológicos. Em geral seu uso se restringe à aquisição de imagens de materiais inorgânicos, tais como pelotas de minério, aço, etc...

Realizou-se, portanto, nesta etapa B1: (1.1) preparação dos corpos de prova biológicos para entrada no equipamento, (1.2) microtomografia com segmentação da imagem, (1.3) reconstrução e tratamento da imagem.

Nas fotos abaixo, apresentamos o microtomógrafo, durante seu uso no Experimento B. $\mathrm{O}$ equipamento usado foi o microtomógrafo Xradia 510 Versa (Figura 6), voltagem $80 \mathrm{Kv}$, $7 \mathrm{~W}, 1601$ projeções, tempo de exposição $0.3 \mathrm{~s}$ e Binning 2, com tempo total de varredura de $1.3 \mathrm{hs}$.

Figura 6 - Microtomógrafo (LPDI) durante a microtomografia do fruto do amendoim

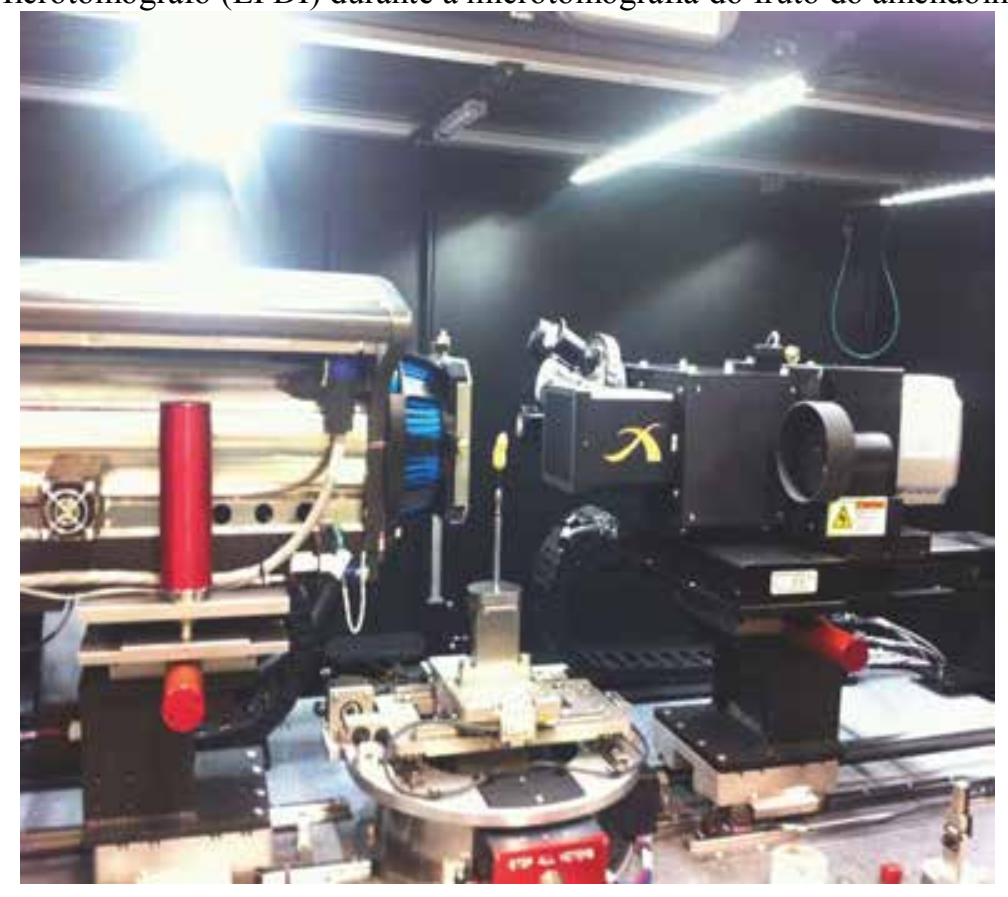

Fonte: fotos da autora

Após calibragem do equipamento para materiais biológicos, microtomografou-se a vagem do amendoim. As amostras de amendoins passaram por um processo de preparação: (1) seleção quanto a sua integridade física e (2) fixação a suportes internos do equipamento (para garantir bom resultado de imagem).

Em seguida o equipamento iniciou a microtomografia com o auxílio do software Scout and Scan Control System (Figura 7), e uma vez adquiridos os dados primários das camadas usou-se o software XM Reconstructor Cobe Beam 10, para reconstrução da imagem 3D da 
vagem do amendoim (Figura 8). Esses dois momentos do processo podem ser constatados nas imagens, a seguir.

Figura 7 - Imagens adquiridas no microtomógrafo com a sequência de camadas da vagem do amendoim, usando-se o software Scout and Scan Control System

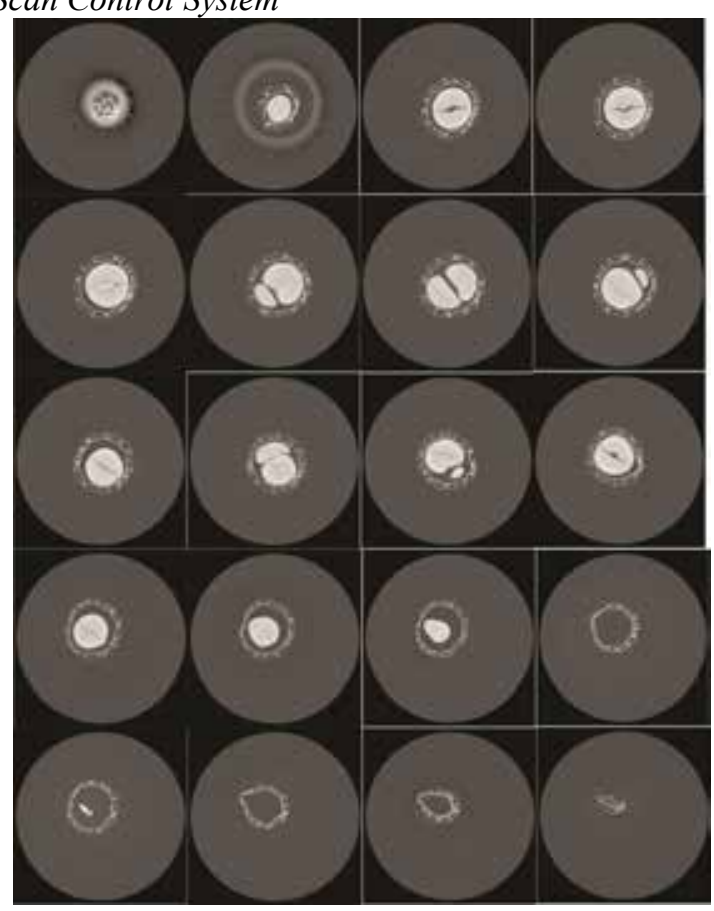

Fonte: imagem da autora

Figura 8 - Reconstrução da imagem da vagem do amendoim microtomografado no Xradia 510 Versa com o software XM Reconstructor Cobe Beam 10.
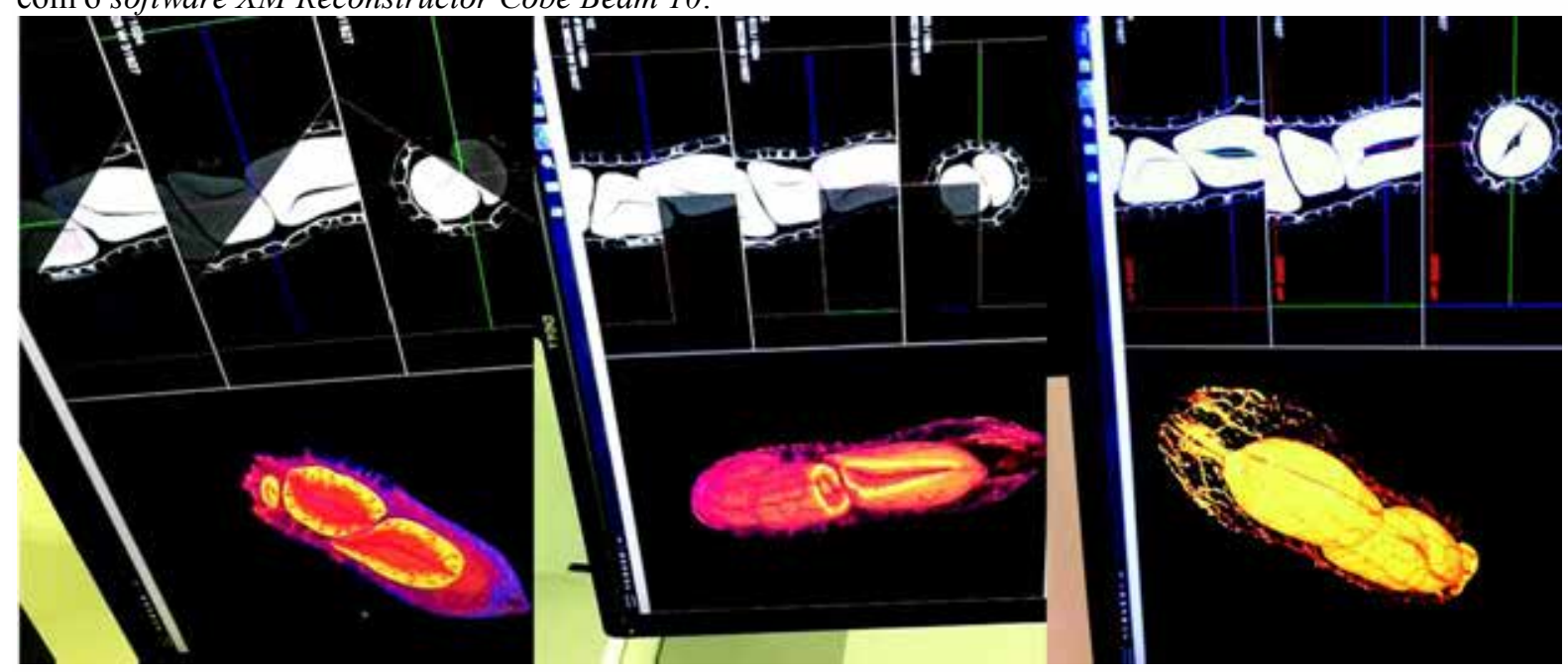

Fonte: imagem da autora

Com o auxílio dos softwares Fiji e Geomagic foi possível tratar digitalmente as imagens adquiridas, obtendo assim mais detalhes e dados primários (Figura 9). 


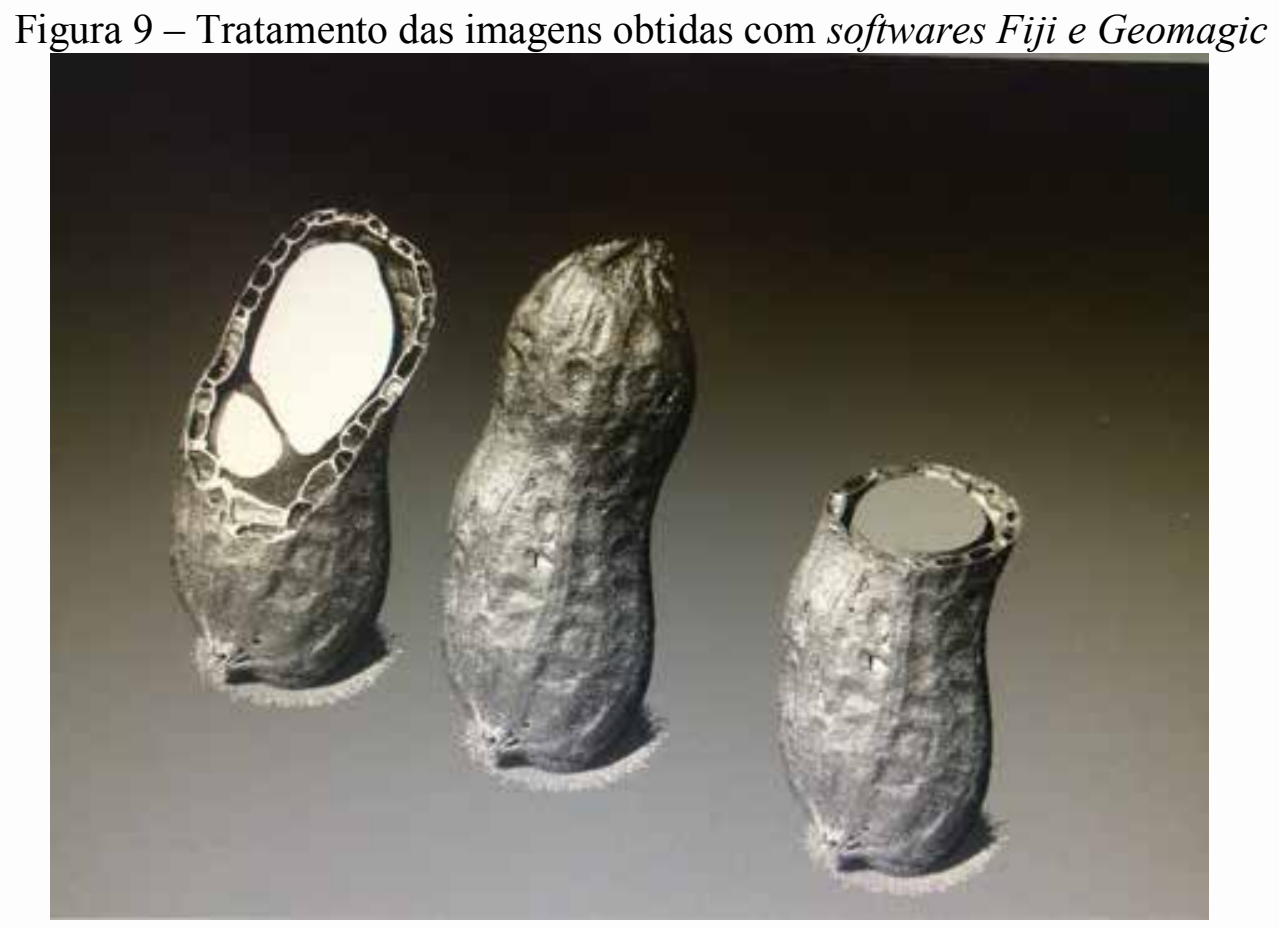

Fonte: imagem da autora

As imagens adquiridas com o microtomógrafo e tratadas digitalmente com os softwares, revelaram o que não conseguiu-se observar a "olho nú": que a estrutura da casca da vagem do amendoim é alveolar e não multicamadas com depressões, como inferiu-se no Experimento A (sem uso de novas tecnologias). Dessa forma compreendeu-se que devido à estrutura alveolar a casca é leve e ao mesmo tempo resistente.

$\mathrm{Na}$ montagem abaixo (Figuras 10 e 11) compara-se: o desenho representativo da observação a "olho nú" do amendoim (com as fibras, multicamadas e depressões); e as imagens do mesmo, adquiridas com o microtomógrafo, nas quais pode-se constatar a estrutura alveolar da casca.

Figura 10 - Comparação entre: representação da casca do amendoim após observação a "olho nú" (a) e imagens adquiridas pelo microtógrafo do amendoim, evidenciando sua estrutura alveolar (b)

(a)

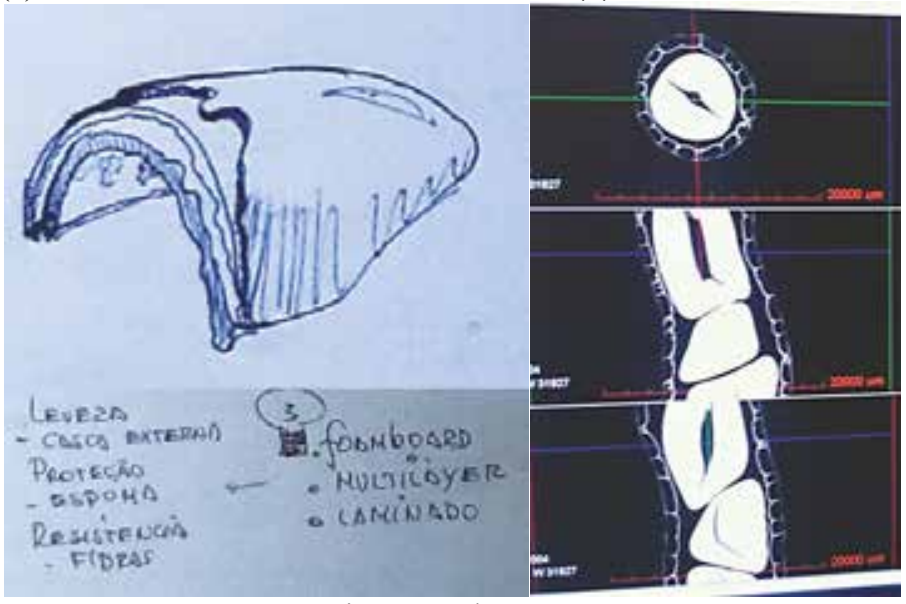

Fonte: imagem da autora

(b)

\begin{abstract}
(1)
\end{abstract}

$$
\text { (1) }
$$


Figura 11 - Comparação entre: representação da casca do amendoim após observação a "olho nú" (a) e imagens adquiridas pelo microtógrafo do amendoim, evidenciando sua estrutura alveolar (b) (fotos da autora).

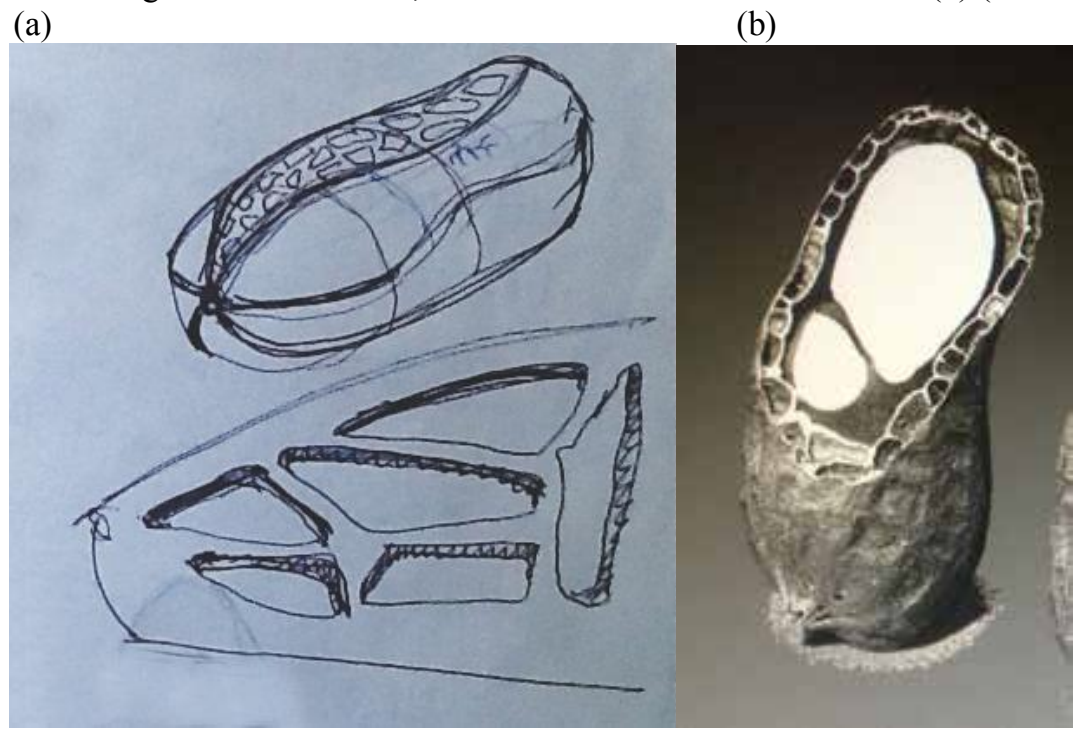

Fonte: imagem da autora

A etapa B2 visou entender as funções do fruto do amendoim. Tratou-se de identificar uma característica, mecanismo, processo, que faz alguma coisa (uma função) para esse organismo. São as "coisas" que a estratégia faz para o organismo, e o contexto onde essa função é desejada. O uso das tecnologias digitais nessa etapa permitiram uma nova abordagem mais reveladora, precisa e acurada para as funções relacionadas às abstrações biológicas da vagem do amendoim, conforme detalhado no quadro abaixo (Quadro 3).

Quadro 3 - Abstrações biológicas da vagem do amendoim e funções refinadas VAGEM DO AMENDOIM

\begin{tabular}{|c|c|}
\hline Estratégias biológicas abstraídas & Funçöes \\
\hline Forma integral, adaptável a diferentes quantidades de sementes. & Permitir adaptaçōes dimensionais \\
\hline $\begin{array}{l}\text { Fragilidade em funçajo de duas fendas presentes na casca na regiáo } \\
\text { longitudinal da vagem (uma espécie de "soldagem" do carpelo da } \\
\text { vagem no processo de crescimento), que "quebra" por meio de } \\
\text { pressáo intencional localizada, disponibilizando as sementes } \\
\text { sem danifić-las. }\end{array}$ & $\begin{array}{l}\text { Abrir uniformemente por meio de pressão } \\
\text { localizada, permitindo acesso ao conteúdo } \\
\text { quando desejado e sem danificá-lo. }\end{array}$ \\
\hline $\begin{array}{l}\text { Amadurecimento do fruto embaixo da terra, } \\
\text { permitindo proteçăo contra predadores. }\end{array}$ & $\begin{array}{l}\text { Promover segurança ao conteúdo contra } \\
\text { agentes externos. }\end{array}$ \\
\hline Impermeabilidade & Proteger contra umidade. \\
\hline $\begin{array}{l}\text { Casca rigida, composta por estrutura alveolar, fibras longitudinais } \\
\text { e multicamadas de materiais. }\end{array}$ & $\begin{array}{l}\text { Resistir a quedas, amassamentos, torção, } \\
\text { punção e impacto, utilizando-se o minimo de } \\
\text { material }\end{array}$ \\
\hline Casca leve, devido à estrutura alveolar. & Ser leve e ao mesmo tempo resistente \\
\hline $\begin{array}{l}\text { Propriedades de barreira da casca contra agentes externos } \\
\text { aumentadas em funçáo da estrutura alveolar (presença de ar que } \\
\text { é isolante). }\end{array}$ & Preservar por mais tempo o conteúdo \\
\hline
\end{tabular}

Fonte: quadro da autora 
Mapeadas e refinadas as estratégias e funções do amendoim, e definido o contexto (embalagem), a próxima etapa (B3 - brainstorm 1) foi a de gerar ideias, combinando esses elementos para resolver problemas. Então, perguntou-se: que problemas pode-se resolver por analogias, ou seja, com a transferência de estratégias abstraídas do amendoim para o design de embalagem?

Para auxiliar nessa transferência, contou-se com a participação, em sessões criativas, de designers com habilidades em: desenho e sketches, no uso de softwares para modelagem tridimensional (Rhinoceros e Solidworks), conhecimentos técnicos e práticos no uso de impressoras 3D (Cube Pro, Felix e Makerbot) para materialização por meio de prototipagem rápida.

Os desenhos abaixo representam algumas ideias (dentre inúmeras) geradas no brainstorm 1 (Figura 12).

Figura 12 - Desenho à mão livre representando ideia para embalagem, usando analogia com a estrutura alveolar da vagem do amendoim

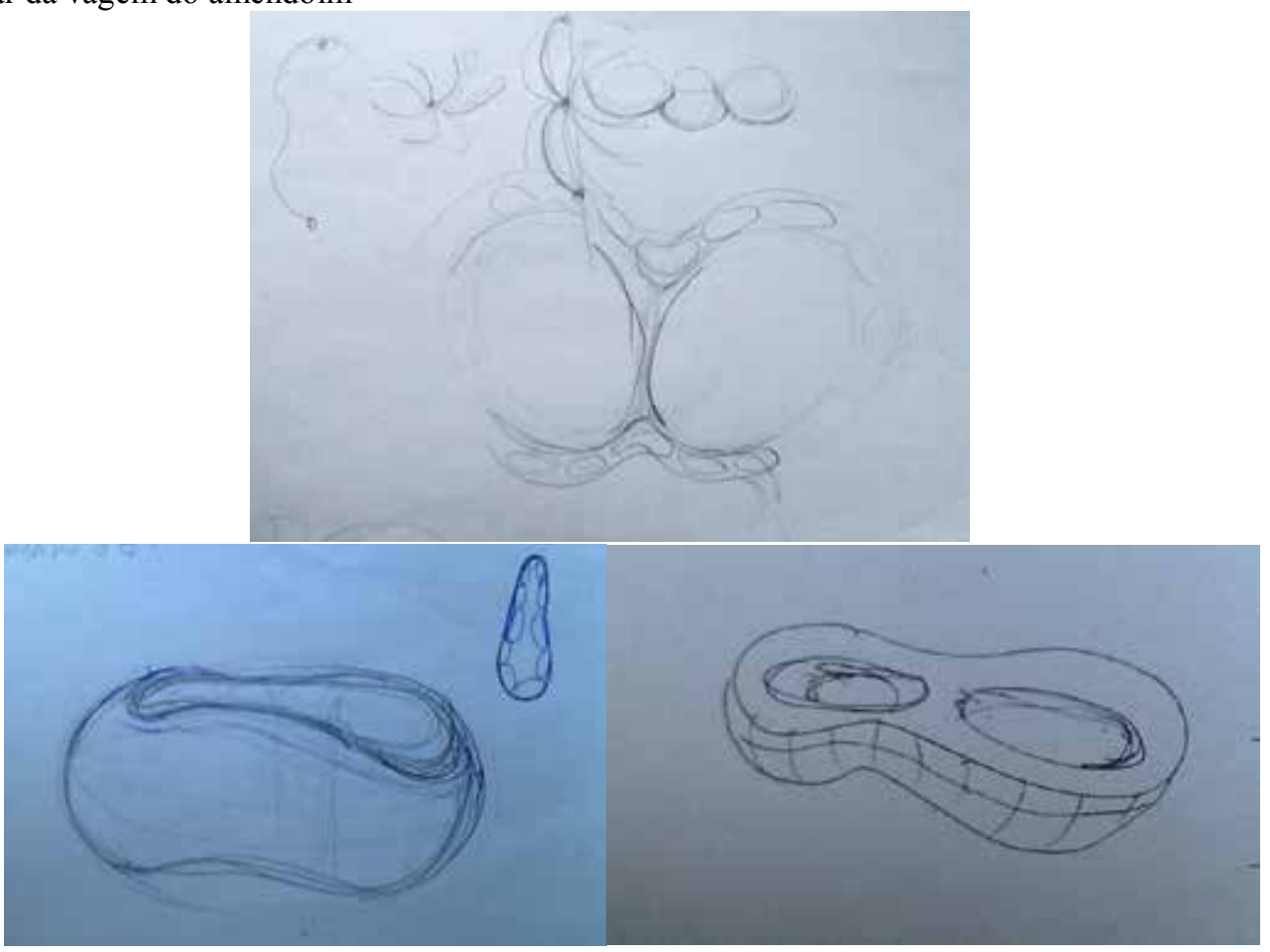

Fonte: desenho da autora 
Modelou-se, também, digitalmente com o software Solidworks (Figura 13).

Figura 13 - Detalhe do corte no volume, para visualização das estruturas alveolares projetadas (modelagem no Solidworks).

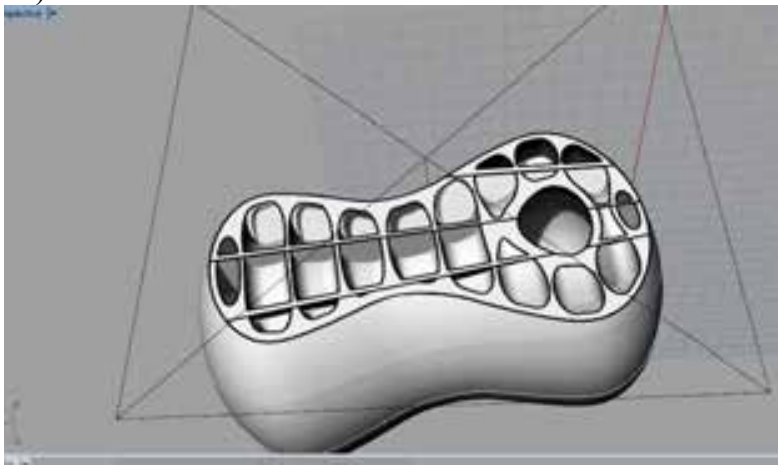

Fonte: imagem da autora

A etapa B4 - emular conceitos de Design, visou aprimorar as melhores ideias do brainstorm 1 a fim de desenvolver conceitos de design. A emulação considera aspectos de forma, configuração, construção, estrutura, escala, padrões e materiais. Utilizou-se o software Solidworks para modelar digitalmente os conceitos (Figura 14), e a impressora 3D Makerbot para materializá-los.

O primeiro conceito de design (a) desenvolvido (Figura 14) possuía configuração formal e estrutural muito similar à vagem do amendoim: resistência a quedas e amassamento, pelas camadas de fibras de celulose e material proteico, e proteção com rigidez e leveza, por meio de estruturas alveolares.

$\mathrm{Na}$ emulação sentiu-se necessidade de dimensionar o volume interno para que o mesmo acomodasse algum tipo de alimento que precisasse de proteção elevada, simulando uma embalagem. Decidiu-se por embalar um ovo, pois a fragilidade do mesmo impõe funções protetivas elevadas para que não quebre ao longo da cadeia de distribuição.

Figura 14- Detalhe de conceito de design (a) de embalagem para um ovo (Modelado no Solidworks )

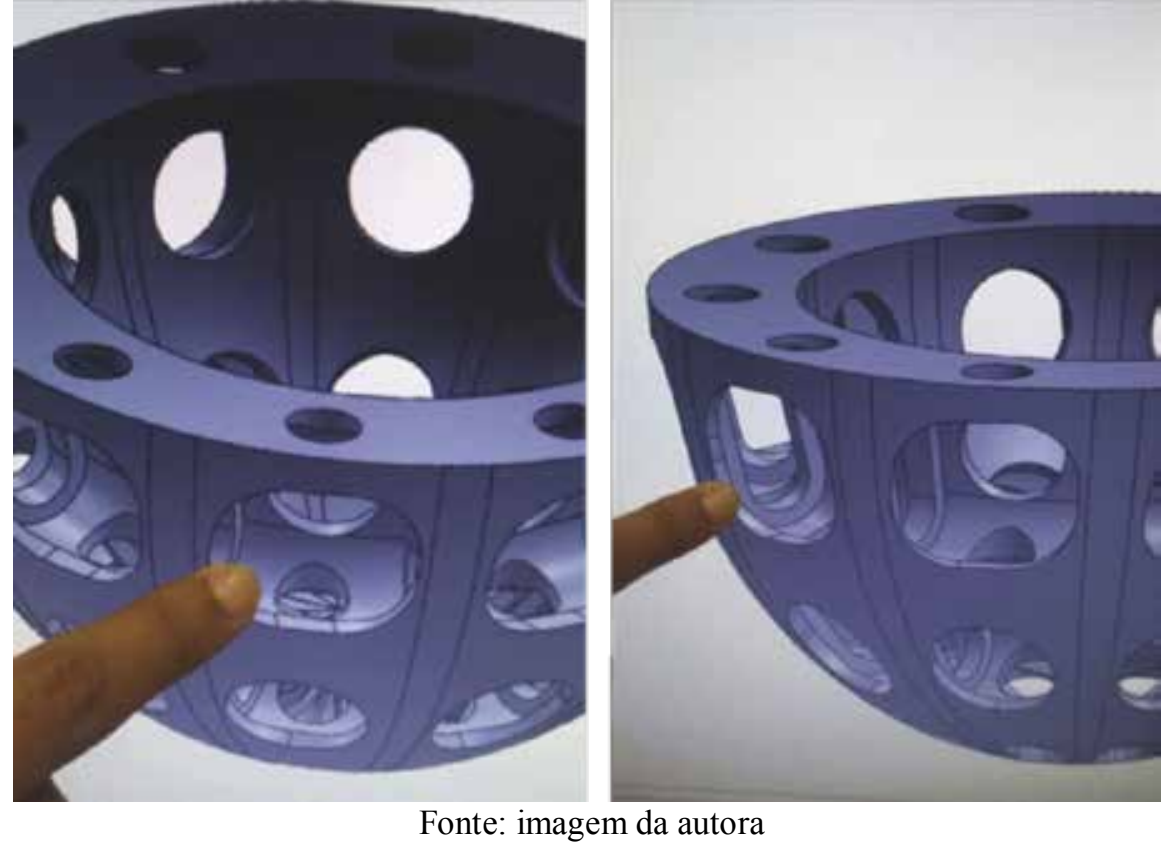


Foram executados protótipos rápidos na impressora 3D, para realizar testes de queda $\mathrm{e}$ impacto e avaliar a proteção ao ovo que esse conceito (a) estava propiciando.

Nos testes de queda constatou-se que o material usado nos protótipos (filamento PLA), por ter dureza elevada, não estava fazendo a estrutura da embalagem proteger o ovo absorvendo para si o impacto. Ao contrário, estava transferindo todo impacto diretamente para o ovo, fazendo-o quebrar.

Pesquisou-se, portanto, materiais de impressão 3D com menos dureza e descobriu-se os filamentos NinjaFlex (elastômero termoplástico) e o SemiFlex (elastômero termoplástico com menor maciez). O experimento de prototipagem na Makerbot com novos filamentos flexíveis e macios foi crucial para que esse conceito (a) absorvesse impacto, e desta forma protegesse melhor o ovo (Figura 15).

Figura 15 - Protótipo do conceito de design (a) executado na Makerbot com filamento NinjaFlex

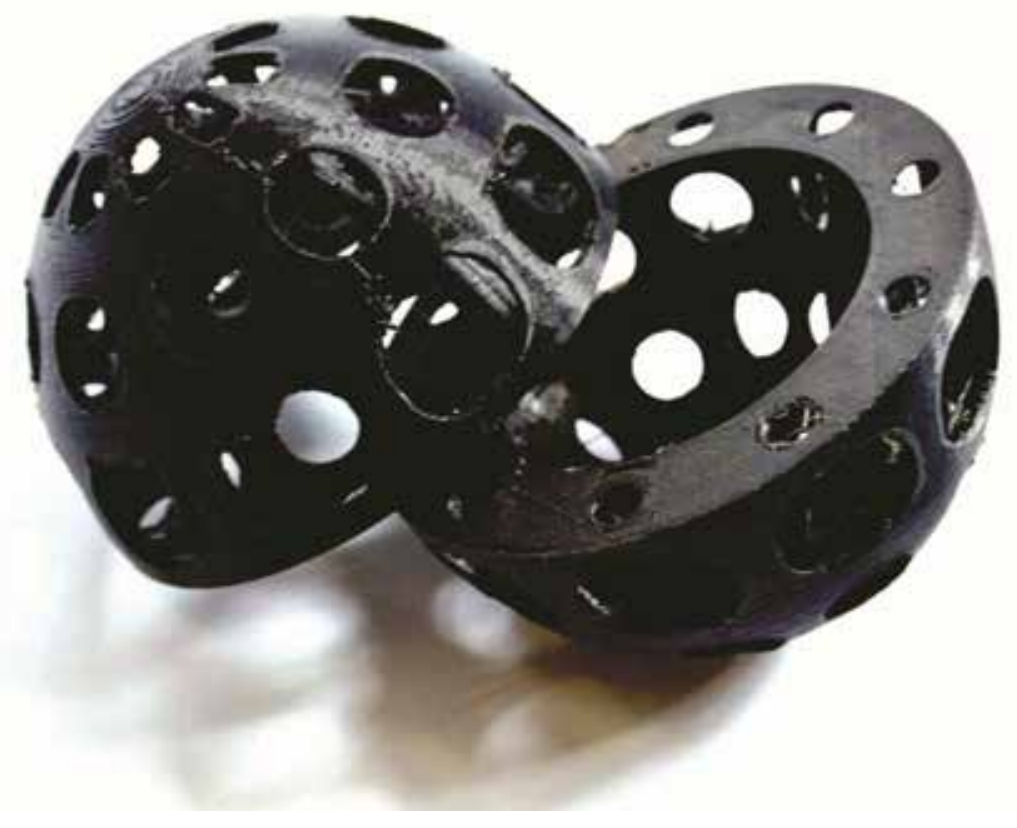

Fonte: fotos da autora

Na etapa B5 - brainstorm 2, outras sessões criativas foram realizadas e novas ideias geradas para o desenvolvimento de novos conceitos de design. Seguiu-se com a mesma metodologia, focando em explorar analogias com alvéolos observados na vagem do amendoim para posterior transferência desse princípio para o design de embalagem.

As melhores ideias do brainstorm 2 (Figura 16) foram selecionadas para aprimoramento, na etapa B6. Considerou-se, portanto, aspectos de forma, configuração, construção, estrutura, escala e padrões para que as ideias evoluíssem para novos conceitos de design biomimético. Nessa etapa utilizou-se o software Solidworks e a impressora 3D Felix e Makerbot, usando filamentos PLA e NinjaFlex. 
Figura 16 - Desenhos à mão explorando analogias com alvéolos da vagem do amendoim

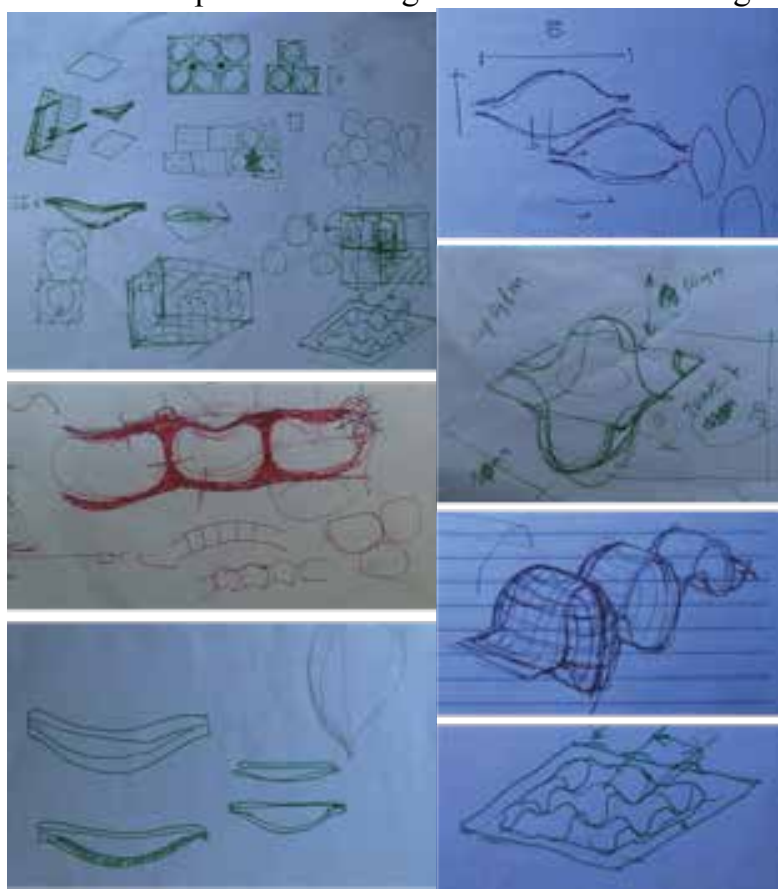

Fonte: desenhos da autora

Finalmente na etapa B7 novos conceitos foram gerados e o mais promissor (b) - (Figura 17) encorajou novas explorações conceituais e de desenvolvimento técnico para concretização do objetivo geral pretendido nessa pesquisa: desenvolver soluções conceituais inovadoras para embalagem, a partir da biomimética, apoiada por novas tecnologias digitais (microtomografia e impressão 3D).

Figura 17 - Modelagem 3D digital do conceito promissor (b) - placa alveolar (modelagem 3D com Solidworks)

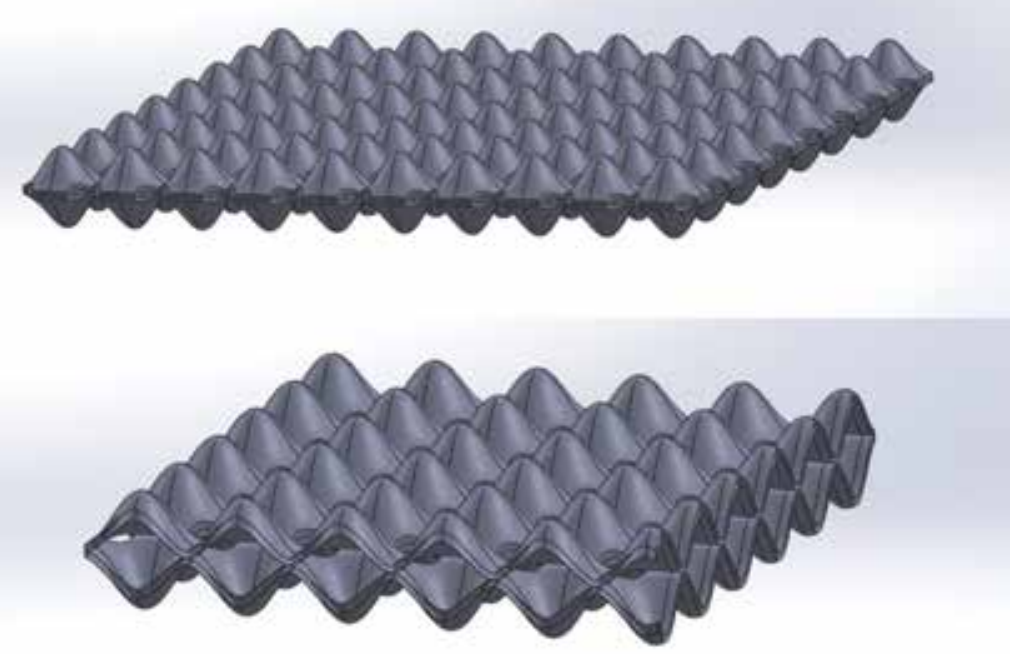

Fonte: imagem da autora 
Executou-se protótipos rápidos na impressora 3D Felix (Figura 18), com o filamento NinjaFlex (elastômero termoplástico).

Figura 18 - Impressão 3D do conceito (b) na impressora Felix com NinjaFlex.

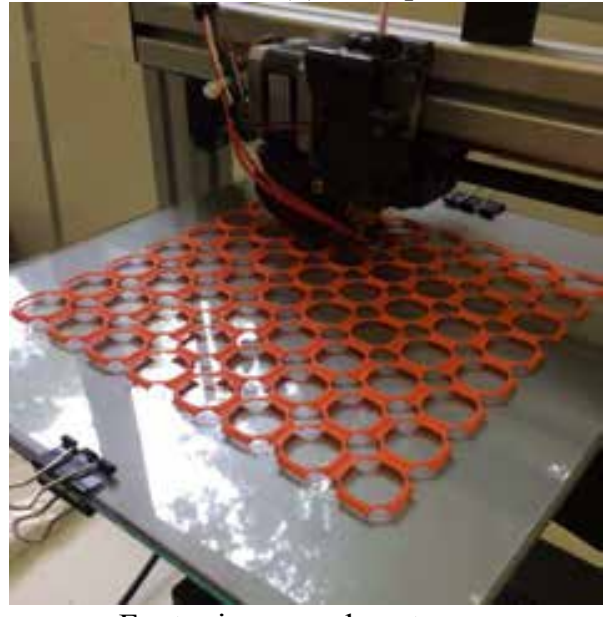

Fonte: imagem da autora

O experimento de prototipagem 3D gerou uma manta flexível e adaptável a diversas aplicações para embalagem (Figura 19).

Figura 19 - Protótipo do conceito promissor placa alveolar "face simples" medindo $10 \times 10 \mathrm{~cm}$. Impresso em 3D (impressora Felix com filamento NinjaFlex).
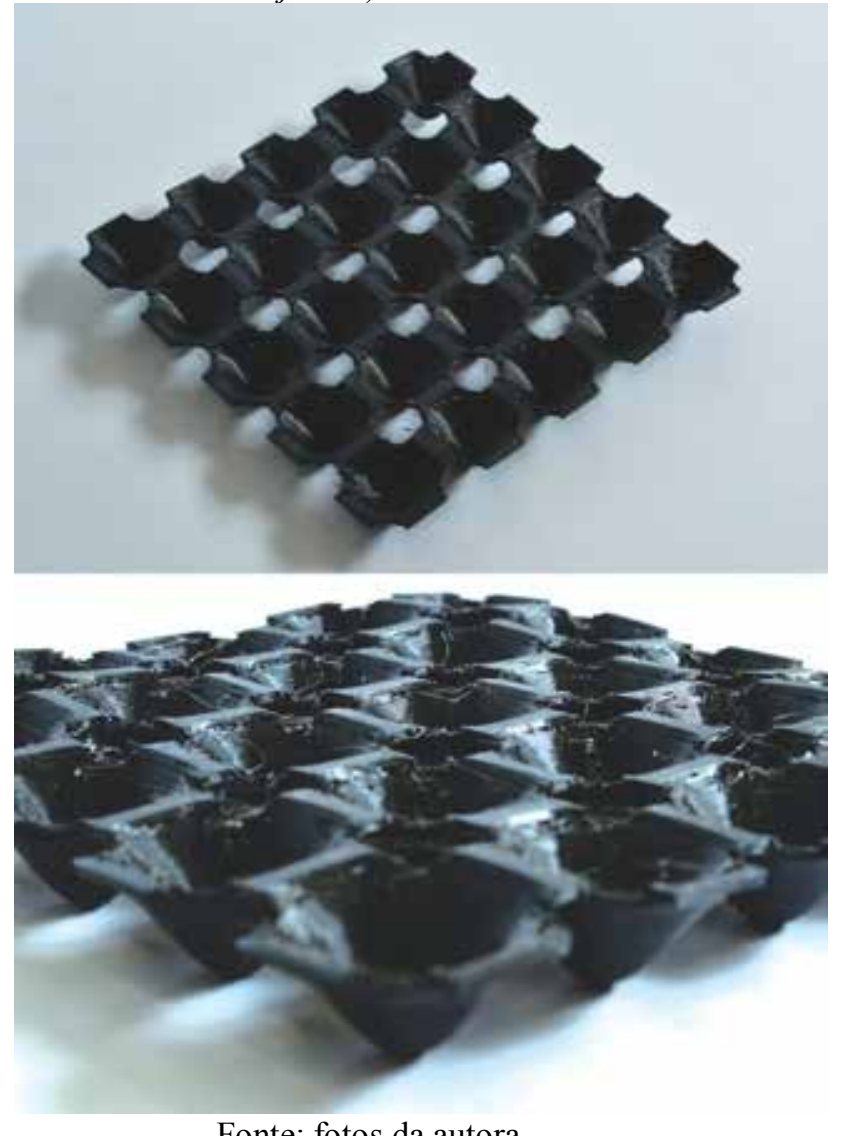

Fonte: fotos da autora

DATJournal v.2 n.2 2017 


\section{Conclusão do Experimento B}

Constatou-se que as novas tecnologias digitais (utilizadas no Experimento B) de aquisição de imagem por meio de microtomografia, reconstrução da imagem, tratamento dessas imagens digitalmente, permitiram uma investigação não invasiva, não destrutiva, detalhada, reveladora, precisa e acurada da vagem do amendoim, ampliando a visão e conhecimento do designer por meio da aquisição de dados primários, colaborando, enfim, para o refinamento das abstrações de estratégias biológicas realizadas no Experimento A, e para a geração de ideias (brainstorm) do Experimento B. É importante frisar o uso inovador do equipamento de microtomografia na aquisição de imagens de materiais biológicos.

Os principais refinamentos das abstrações - que não foram possíveis a "olho nú" relacionaram-se à constatação da presença de alvéolos e de duas fendas longitudinais na casca da vagem. Abstraídas e refinadas as estratégias (por meio das novas tecnologias digitais) e definidas as funções do fruto do amendoim, geraram-se ideias para embalagens. Dessa vez percebeu-se um incremento na quantidade de associações e na qualidade e variedade das analogias, que extrapolaram os aspectos meramente formais do organismo, demonstrado que o pensamento criativo lateral foi estimulado pelas imagens adquiridas com as novas tecnologias.

No Quadro 4, abaixo, compara-se as estratégias observadas antes do uso das novas tecnologias (Experimento A) e depois do uso das novas tecnologias (Experimento B).

Quadro 4 - Comparativo das estratégias biológicas abstraídas do amendoim nos Experimentos A e B

\section{VAGEM DO AMENDOIM}

\begin{tabular}{|c|c|}
\hline $\begin{array}{l}\text { Estratégias biológicas abstraidas: } \\
\text { Experimento A (sem novas tecnologias) }\end{array}$ & $\begin{array}{l}\text { Estratégias biológicas abstraidas: } \\
\text { Experimento B (com novas tecnologias) }\end{array}$ \\
\hline Forma integral, adaptsvel a diferentes quantidades de sementes. & Forma integral, adaptável a diferentes quantidades de sementes. \\
\hline $\begin{array}{l}\text { Fragilidade na regiaso longitudinal da vagem, } \\
\text { que "quebra" por meio de presssó, } \\
\text { disponibilizando as sementes sem danificá-las. }\end{array}$ & $\begin{array}{l}\text { Fragilidade em funçio de duas fendas presentes na casca na regiáo } \\
\text { longitudinal da vagem (uma espécie de "soldagem" do carpelo da } \\
\text { vagem no processo de crescimento), que "quebra" por meio de } \\
\text { pressāo intencional localizada, disponibilizando as sementes } \\
\text { sem danifica-las. }\end{array}$ \\
\hline $\begin{array}{l}\text { Amadurecimento do fruto embaixo da terra. } \\
\text { permitindo proteçăo contra predadores. }\end{array}$ & $\begin{array}{l}\text { Amadurecimento do fruto embaixo da terra. } \\
\text { permitindo proteçăo contra predadores. }\end{array}$ \\
\hline Impermeabilidade & Impermeabilidade \\
\hline $\begin{array}{l}\text { Casca rígida, composta por conjunto de fibras longitudinais e } \\
\text { multicamadas de materiais. }\end{array}$ & $\begin{array}{l}\text { Casca rigida, composta por estrutura alveolat, fibras longitudinais } \\
\text { e multicamadas de materiais. }\end{array}$ \\
\hline \multirow[t]{2}{*}{ Casca leve, devido à diminuição da espessura nas depressōes. } & Casca leve, devido à estrutura alveolar. \\
\hline & $\begin{array}{l}\text { Propriedades de barreira da casca contra agentes externos } \\
\text { aumentadas em funçáo da estrutura alveolar (presença de ar que } \\
\text { é isolante). }\end{array}$ \\
\hline
\end{tabular}

Fonte: quadro da autora

Também utilizou-se no Experimento B, novas tecnologias digitais de modelagem tridimensional (softwares Rhinoceros e Solidworks), prototipagem rápida em impressoras 3D (CubePro, Felix e MakerBot), que possibilitaram a materialização rápida de protótipos em 
diversas configurações e materiais, permitindo a exploração de diversos conceitos de design e a validação do mais promissor para inovação de embalagem bioinspirada.

\section{Conclusão}

Um panorama diversificado de soluções disponíveis na natureza podem lançar-nos à criação de produtos inovadores, por meio da biomimética e das novas tecnologias digitais.

Ao final dessa pesquisa, graças ao processo de design exploratório e experimental, chegou-se a um conceito de design, que foi resultado de um desdobramento das analogias geradas entre biologia (vagem do amendoim) e design (embalagem), potencializadas por novas tecnologias digitais (microtomógrafo e impressão 3D). Esse conceito propõe um sistema inovador para embalagem que: aumenta a proteção e conservação, reduzindo o desperdício, permite adaptação a diferentes formatos e dimensões do conteúdo a ser embalado, e otimiza o uso de materiais e processos.

O resultado final alcançado faz-nos vislumbrar uma série de ampliações dessa pesquisa, como por exemplo: viabilidade técnica e implementação industrial do sistema criado, a fim de que seu uso possa ser generalizado em larga escala; integração dos princípios encontrados na natureza à soluções de design sustentáveis e ambientalmente corretas; sistematização do uso das novas tecnologias digitais na transferência da inteligência presente na natureza, para o design.

\section{Referências}

BENYUS, Janine. Biomimética: inovação inspirada pela natureza. São Paulo: Ed. Pensamento-Cultrix, 2003.

BENYUS, Janine, BAUMEISTER, Dayna. Packaging Tips from the Porcupine Fish. USA: Biomimicry Institute, 2002.

BIOMIMICRY 3.8. Biomimicry Design Lens. Licenced under creative commons BY-NCND. Disponível em: http://biomimicry.net/about/biomimicry/biomimicry-designlens $>$. Acesso em: 21 nov. 2014.

EMTECH BRASIL 2015. Viver em uma Cidade Inteligente, hoje. Rio de Janeiro: MIT Technology Review, 2015.

GENTNER, Dedre; MARKMAN, Arthur B. Structure Mapping in Analogy and Similarity. USA: American Psychological Association, 1997.

GORDON, William J.J. Synectics: The Development of Creative Capacity. New York: Harper \& Brothers, 1961.

OLIVEIRA, Eurico Cabral de. Introdução à biologia vegetal. São Paulo: Editora da Universidade de São Paulo, 2008.

SHU, L.H. et al. Biologically inspired design. Canadá: CIRP Annals - Manufacturing Technology 60 (673-693), 2011. 
THOMPSON, Darcy. On Growth and Form, 1917.

WORLD PACKAGING ORGANIZATION (WPO). Packaging - An important tool for a sustainable society. USA: World Packaging Organization, 2011

Homepages:

ASK NATURE - The Biomimicry 3.8 Institute, 2008-2016. Disponível em: $<$ http://www.asknature.org>. Acesso em: 5 jan. 2014.

BIOMIMICRY 3.8. The Biomimicry design portal. The Biomimicry 3.8 Institute, 2008-2016. Disponível em: <http://www.biomimicry.org $>$. Acesso em: 5 jan. 2014.

ENCYCLOPEDIA OF LIFE. Disponível em: < http://eol.org/>. Acesso em 5 março 2014.

MASSACHUSETTS INSTITUTE OF TECHNOLOGY. Disponível em:

$<$ http://senseable.mit.edu>. Acesso em: 17 nov. 2015.

O GLOBO. Desenvolvido por Infoglobo Comunicação e Participações S.A, 1996-2016.

Disponível em $<$ http://oglobo.globo.com/sociedade/tecnologia/sensores-big-datarevolucionam-gerenciamento-urbano-18080436>. Acesso em: 27 nov. 2014.

PINTEREST. Disponível em: < http://www.pinterest.com/pin/282178732877521603/>. Acessado em: 20 nov. 2014

PLANTILLUSTRATIONS. Disponível em: <http://www.plantillustrations.org/>.Acesso em 7 dez. 2015. 